\title{
The effects of Learning Organization towards Employees' Innovative Behavior Mediated by Work Engagement (A Study in Indonesia)
}

\author{
Rosiwarna Anwar \\ rwnwar40@yahoo.com; \\ Department of Management, Faculty of Economics and \\ Business \\ University of Indonesia
}

\author{
Siti Hajar Maharani Niode, \\ raniniode@gmail.com \\ Department of Management, Faculty of Economics and \\ Business \\ University of Indonesia
}

\begin{abstract}
Innovation has been regarded as one of the most important aspect in a succesful company. Innovation is not something that could take place in a second, a company has to nurture and develop the innovative behaviors of their employees. Innovative behaviors can be nurtured and developed by continuous learning and developing a learning a culture, or becoming a learning organization. Besides inonovative behavior, a learning organization can also develop a sense of well being, that is work engagement, which in turn can also develop innovative behavior of the employees. This study aims to analyze the effect of learning organization towards employees' innovative behavior and mediated by work engagement using Structural Equation Modelling (SEM) method. Research data were collected from 244 employees of automobile dealers company in several locations acrossIndonesia using questionnaires. The study result showed that learning organization has a positve effect towards work engagement, in which work engagement has a positive effect toward employees' innovative behavior. Also, learning organization has a positive effect towards employees' innovative behavior, which means work engagement has a role of partial mediation.
\end{abstract}

Keywords: learning organization, work engagement, innovative behavior, structural equation modelling.

\section{Introduction}

A global business competition is something that is becoming inevitable for a company. In this globalization era, which marked by tight competition and fast flow of information in every aspects, borders between countries is becoming more and more invisible. According to Kotter (1992) globalization and competition of the markets leads to huge changes, such as knowledge. We have become a knowledge-driven economy. Knowledge driven economy also generates knowledge workers, The innovative potentials in knowledge workers should be nurtured. These innovative potentials can be nurtured by developing their innovative behaviors. Innovative behaviors plays an important role in encouraging employees' ability to innovate, because it can describe employee behavior in developing, reacting, and changing an idea (Scott and Bruce, 1994).
Right now, our society is based on creativity and innovation, human creativity and tacit knowledge can be regarded as the main source of continuous innovation (Nonaka and Takeuchi, 1995; Koskinen and Vanharanta, 2002). Behavioral innovation can be influenced by things such as transformational leadership, organizational learning capabilities, and knowledge sharing (Pieterse et al., 2010; Monica $\mathrm{Hu}$ et al., 2009; Wang and Wang, 2012). In order for a company to develop innovative behavior from its employees, the company needs to adopt a learning culture that encourages continuous learning, knowledge sharing, employee empowerment, and social interaction that encourages learning among employees.

Things like continuous learning, knowledge sharing, employee empowerment, and social interaction can be created if an organization is committed to creating and nurturing a learning culture. Companies need to learn through past successes and failures faster and better, so that companies can gain and maintain their competitive advantage. In order to do this, the company needs to transform into a learning organization (Marquardt, 2002).

The concept underlying the first learning organization was proposed by Senge (1990). Organizational learning is an organization that focuses and is committed to individual development, and active learning, which aims to gain competitive advantage over competitors (Somunoğlu et al., 2012). Oneren (2008), affirms that every experience gained in the learning organization will contribute to the learning process and this will further contribute to the motivation of the members and encourage to work in teams.

Currently, many companies are continuously implementing good learning culture, in order to become a learning organization. These companies have been listed in Global Most Admired Knowledge Enterprises (Global MAKE). The winning companies in Global MAKE have proven that becoming a learning organization can improve company performance. Winners of the Global MAKE listed on the NYSE / NASDAQ show higher Total Return to Shareholders (TRS), Return on Revenues (ROR), and Return on Assets (ROA) when compared to non-winning companies. Companies that often win in Global MAKE are Accenture, Microsoft, Alphabet (holding company from 
Google), Apple, Tesla Motors, Toyota, and many other companies. These companies are also always ranked top 10 in the list of "Most Innovative Companies" issued by Boston Consulting Group (BCG). In addition to the culture of learning, innovative behavior can also be influenced by intrinsic motivation. Hakanen et al. (2008) also suggested that individual work engagement encourages individual initiative and further encourages innovation. They find that if employees have good work engagement, then it can make them proactive and responsible which further encourages innovation. Frederickson (2001) also noted that work engangement owned by employees will encourage them to feel more positive and can think creatively and explore an idea. Based on these findings, work engagement can be considered to have a mediating role in the effects between learning organization and innovative behavior.

While there is a logical relationship in work engagement and innovative behavior that employees have, there is little research on the subject. If, innovative behavior of employees can be developed within the organization, then a framework or system within the organization that can link work engagement with leadership, learning and other supporting things in an organization is required. Therefore, the purpose of this research is to find out the mediating effect of work engagement in its influence between learning organization and innovative behavior.

\section{Theoretical Foundation}

\section{Innovative Behavior}

According to West \& Farr (1996), the terms creativity and innovation can not be separated from each other, but there is a considerable difference between these two terms. Creativity is thought to be the creation of a new and useful idea (Mumford \& Gustafson, 1988) besides creativity can also be defined as doing something new for the first time or the creation of new knowledge (Woodman, Sawyer, \& Griffin, 1993). Furthermore, according to Amabile (1996) creativity is a process of producing new ideas and useful by an individual or small group that work together.

While Kanter (1983) defines innovation as a process that uses new problem-solving ideas and ways, then Van de Ven (1986) reveals that innovation is a development and implementation of new ideas by individuals involved in an institution. Amabile (1996) defines innovation as a success of the implementation of a creative idea within an organization, through this definition, an idea can be a product, process, service, and also a new policy within the organization. Through the above definitions can be concluded that innovation is a creation, acceptance, and implementation of new ideas, processes, products and services.

Furthermore, experts also consider innovation is not just the creation of an idea (idea generation), innovation is a process with various stages that can be influenced by various social factors. Therefore, Scott and Bruce (1994) differentiate between individual-level innovation and individual-level innovation. Individual-level innovation is associated with innovative behavior, which is defined as actions aimed at finding, developing and applying new ideas and solutions for current situation. Furthermore Janssen (2000) defines innovative behavior as the deliberate creation, introduction, and application of new ideas in work, group or organizational roles to be useful to work, groups, or organizations, this definition based on West and Farr (1989) and West (1988).

Furthermore, the stages of innovative behavior issued by Scott and Bruce (1994) were again simplified by Janssen (2000), being:

\section{Idea generation}

Individual innovation begins with the creation of an idea, that is, the creation of new and useful ideas. Things that can trigger this are issues related to work, incongruity, discontinuities, and also the emergence of new trends.

\section{Idea promotion}

Furthermore, new ideas or solutions are promoted to potential allies, such as colleagues to superiors. This can be done through the involvement of the individual in social activities, in order to support and provide the individual the power necessary to pursue his new idea.

\section{Idea realization}

The final stage is to create a prototype or model of innovation that can be perceived as immediate results in work, group, or organization. Simple innovation requires only an individual to solve it, while for complex innovation requires cooperation between individuals who have diverse

knowledge and competence (Kanter, 1988)

\section{Learning Organization}

One expert who pioneered the learning organization was Peter Senge, according to Senge (1990), the definition of organizational learning is the organization where people can continually expand their capacity to create the things they really want, the place where new ideas can widespread and also be developed, a place where collective aspirations can occur freely, and a place where people can constantly learn to look from a common point of view together.

Meanwhile, according to Marquardt who also issued a book on learning organization, defines that learning organization as an organization that can effectively, collectively and continuously transform to become a good manager and use knowledges to empower the learning process, and utilize existing technology to maximize learning and production that takes place within the organization.

In both definitions above Senge and Marquardt, many use the word continuously. This means that learning that takes place within a learning organization is not just a responsive action or occurs just once, but learning has become a system within the organization. 
Marsick \& Watkins (2003) defines the learning organization as an organization that systematically instills a learning culture for old employees or future employees and is supported through adequate learning facilities. In order to achieve a proper organizational learning, it is necessary to make changes. These changes can occur through rules, values, system relationships and structures, and all the principles that underlie an organization. Learning organizations can increase the intensity of learning through changes in strategy, structure, spare time (slack), and ideology (Meyer, 1982)

\section{Work Engagement}

According to research published by Schaufeli and Bakker (2003) on work engagement, which is based on Maslach and Leiter (1997). Schaufeli and Bakker (2003) define work engagement as a positive and satisfying state of mind that has three characteristics, namely; vigor, dedication, and absorption (2003). Schaufeli and Baker also consider that work engagement is not something that happens suddenly and is not specific, but work engagement refers to things that are more persistent and self-absorbing and not focused on a particular object, individual and behavior

According to the definition above, there are 3 dimensions of work engagement namely:

\section{Vigor}

Vigor is reflected through high levels of energy and mental endurance at work, as well as the willingness to invest in work and perseverance.

\section{Dedication}

Dedication refers to high involvement while working and feeling significant, enthusiasm, inspired, pride, and is challenged while working.

\section{Absorption}

Absorption is reflected through full concentration and feeling drifting into the work, where the worker feels the time passes and feel burdened to leave work unfinished.

\section{Research Model}

This study usea a research model adapted from journals compiled by Yu Kyoung Park, Ji Hoon Song, Seung Won Yoon, and Jungwoo Kim entitled "Learning Organization and Innovative Behavior, The Mediating Effects of Work Engagement" issued in 2014 .

The research model undertaken by Park et al. (2014) was conducted on 326 employees of various companies engaged in various industries such as IT, manufacturing, construction, and electronics located in South Korea. Results from research conducted by Park et al. (2014) indicates that the influence of learning organization on innovative behavior is fully mediated by work engagement involvement. Based on the research model that has been described, the statistical hypothesis in this study are as follows:

\section{H1: Learning organization positively affects employees innovative behavior}

\section{H2: Learning organization positively affects work engagement.}

The positive impact of organizational learning has been extensively researched, such as research conducted by Skerlavaj et al. (2010), they conducted research in which included companies in South Korea, they found that the learning organization culture adopted by the company can determine the culture of innovation and innovation in the field of services, technical and administrative processes within the company. Activities that involve the creation of knowledge can also positively influence the creativity of teamwork (Yoon et al., 2010). Research conducted by Tseng (2011) and Atak (2011) also found that the learning organization culture had an effect on the commitment and engagement owned by the employees. A survey conducted by the American Society for Training and Development shows that an organization that encourages learning culture, provides quality training, and gives coaching to its employees can increase employee engagement. The learning organization has become one of the most studied variables in terms of promoting innovation in the organization, not only that, by becoming a learning organization as well as organizing the organization to improve empoloyee engagement. Research conducted by Amabile (1996), suggests that existing resources in organizations such as employees who have the ability and knowledge of appropriate, allocation of funds, systems and effective processes, and relevant training can affect the occurrence of innovation. Hirst et al (2009) also published research based on research conducted by Amabile (1996) which suggests that there is a positive influence between learning behavior in teams (team learning behavior) and employee creativity.

\section{H3: Work engagement positively affects employees'} innovative behavior.

There have been studies that reveal the positive effects of workgroup on organzational outcomes such as employee personal initiatives (Hakanen et al, 2008) extra-role performance (Bakker et al., 2004), and job performance (Bakker and Bal, 2010). According to Hakanen et al. (2008) work engagement can enhance employees' personal initiatives which can further encourage innovation within the scope of work. Employees with high work engagement, work in maximum capacity and proactively solve problems, other than that when a person has a high work engagment then he / she will feel positive feelings (Bakker and Demerouti, 2008) and this will encourage the person to seek and receive Information or new experiences and apply them to work (Frederickson, 2001). And, according to Isen (2001), positive feelings affect the ability of a person in solving problems, flexibility, and innovation.

H4: Work engagement mediates the effect between learning organizations and employee innovative behavior. 
In addition, the mediation role of work engagement on the influence of organizational resources and organizational outcomes has also been widely studied. As research conducted by Bakker and Bal (2010) suggests that work engagement mediates the influence between autonomy and job performance. In addition Salanova and Schaufeli (2008) found that work engagement mediated the influence of job resources, feedback and proactive behavior of employees. A learning organization is closely related to the innovation process, and this innovation can be reinforced by high work engagement. Innovation demands the creation and implementation of a new idea and this requires employees to continually update their skills and knowledge. Thus organizations committed to enhanced work engagement can encourage collaborative relationships to innovate, which in turn can enhance innovation capacity within organizations.

\section{Research Findings}

In this study, data was collected by two methods namely, distributing questionnaires directly in physical form and using an online questionnaire, namely typeform. Before doing the main research, researchers first do pre-test. Pretest aims to test the validity and reliability of the question indicator used in the questionnaire. In this research, data processing and data analysis is done by using SEM (Structural Equation Modeling) method using Lisrel software 8.51.Next, through SEM method, in order to achieve maximum likelihood theory, the respondent required is 5 times from number of indicators. In this study, the indicators used in the questionnaire amounted to 20 pieces of indicators, then the respondents needed are 100 respondents. Next, the respondents of the main-test are 244 respondents.

Based on the results of research reliability and validity test on SEM, all indicators used are valid and reliable. As well as the goodness of fit of the measurement model also shows a good match. After performing the measurement model test, then the measurement model of the structural model also shows good match. After the model is stated as good fit, then the causal relationship needed to be analyezed, in SEM method, a causal relationship analysis is used to know the relation between latent variable used in research hypothesis.



Diagram 1. Path Diagram, SLF and t-value

\section{Diagram 1. Path Diagram, SLF and t-value}

The hypothesis of this study uses one-tailed hypothesis test, and positive influence type, then the t-value generated from the output of structural model needs to be worth $\geq$ 1.645. However, if the t-value shows results that are not in accordance with the criteria, then there is no significance between latent variables, and the research hypothesis will be rejected. Based on the above picture, which presents the value of SLF and t-value, then the hypothesis $1-3$ is stated significant, because it meets the criteria of t-value significance. The organizational learning variable proved to have a positive influence on work engagement variables (value-t $=9.00$, SLF $=0.74)$, then work engagement variables also have a positive direct effect on innovative behavioral variables (value-t $=3.63$; $\mathrm{SLF}=0.34$ ). The calculation of the significance of mediation is done by using SLF values which contain the structural model. Through these calculations, it can be seen that the total effects of organizational learning variables to innovative behavior through work engagement variables is 0.6816 , so it is evident that work engagement variables act as mediation variables. Work engagement acts as a partial mediation, which means that the learning organizational variable can directly influence innovative behavior variables without passing the work engagement variables.

\section{Discussion}

In the first hypothesis, $\mathrm{H} 1$ is significant.Based on the results of data analysis, it can be seen that the organizational learning variables have a positive effect on employee innovative behavior variables. This can be seen through the output of software lisrel 8.51 which shows the t-value $4.45 \geq$ 1.645 which shows significant results. The companies has policies where the employees have to join in a Kaizen competition to make continuous improvement in their company. These companies also have a learning center facility that is specifically intended for its employees in order to improve their competence in the work. In addition, Based on the descriptive analysis of organizational learning variables, the average total obtained was 5.05; This figure indicates that both companies have implemented learning organizations based on a model developed by Marsick and Watkins (2003) quite well.

In the second hypothesis $\mathrm{H} 2$ is significant Based on the results of data analysis has been done, it can be seen that the organizational learning variables have a positive influence on work engagement variables This can be seen through the output of software lisrel 8.51 which shows the t-value $9.00 \geq$ 1.645 which shows significant results. The study, published by Salanova (2005), found that organizational resources can affect work engagement. Salanova (2005) reveals that when a worker feels his organization has enough organizational resources that they will feel more positive energy, they will feel vigorous energy, dedication, and absorption, Where they are part of the work engagement dimension.

In the third hypothesis is significant. Based on the results of data analysis that has been done, it can be seen that work engagement variables have a positive effect on employee innovative behavior variables. This can be seen through the output of the lisrel 8.51 software that shows the t-value of $3.63 \geq 1.645$ which shows significant results. Work engagement is a positive feeling that a person feels, 
according to Young et al. (1997) positive feelings can encourage the acceptance of information and flexible thinking. In addition, according to research published by Sonnentag (2003), revealed that employees who have high work engagement will help these employees in taking the initiative in their work.

In the fourth hypothesis, it is significant. Based on the results of data analysis that has been done, it can be seen that the variable work engagement mediates the influence between learning organizations and innovative behavior of employees. A learning organization is closely related to the innovation process, and this innovation can be reinforced by high work engagement. Innovation demands the creation and implementation of a new idea and this requires employees to continually update their skills and knowledge. Thus organizations committed to enhanced work engagement can encourage collaborative relationships to innovate, which in turn can enhance the capacity of innovation within organizations

\section{Conclusion}

1. The learning organization positively affects employees' innovative behavior.

2. Learning organization positively affects work engagement.

3. Work engagement positively affects employee's innovative behavior.

4. Work engagement of the employees mediates the effects between the learning organization and the employee's innovative behavior.

\section{Managerial Implications}

1. Through the results of research can be seen that the learning organization positively affect the innovative behavior and work engagement of the employees. When referring to the descriptive analysis described in the previous chapter, the total average gained for the learning organizational variable goes to the high category. This means that the company has applied the organizational criteria of learning well. Although the results obtained quite well, the company also needs to continuously improve the organizational culture of learning in every aspect of the company. What a company can do in improving the learning organization culture is; Creating opportunities to learn continuously such as job rotations; giving challenging projects; making Kaizen or other continuous improvement events, encouraging open dialogue, supporting teamwork and learning, creating a system that can store and share learning information, share the same vision among employees, promote good relationships with the business environment, and the strategic support of the corporate leaders.

2. In addition to learning organizations, according to this research, work engagement can also have a positive impact on employee's innovative behavior. Work engagement not only affects innovative behavior, but many other positive organizational outcomes. Work engagement can be improved through such social support from colleagues and superiors, performance feedback, coaching, job autonomy, occupational diversity, and training facilities.

\section{Limitations}

1. Further research can be done on companies that have created significant innovations, both in internal processes or products, in order to measure what things can cause innovation within the company.

2. Further research can include other variables that are considered to have an effect on innovative behavior such as leadership, coaching and mentoring and so forth.

3. This research is a self-report, which only uses individual perceptions of each employee will be the innovative behavior that he did. If, further research can make judgments about others not themselves, then the assessment will be more valid.

4. Further research may include the type of work in the respondent's profile question, whether he or she works in operational or support sections. This is done in order to better explain about innovative behavior in each type of work.

\section{REFERENCES}

[1] Amabile, T. M. (1996). Creativity in context: update to The social psychology of creativity. Boulder, Colo.: Westview Press.

[2] Atak, M., \& Erturgut, R. (2010). An empirical analysis on the relation between learning organization and organizational commitment. Procedia - Social and Behavioral Sciences, 2(2), 3472-3476.

[3] Bakker, A. B., \& Bal, M. P. (2010). Weekly work engagement and performance: A study among starting teachers. Journal of Occupational and Organizational Psychology, 83(1), 189-206.

[4] Bakker, A. B., \& Demerouti, E. (2008). Towards a model of work engagement. Career Development International, 13(3), 209-223.

[5] Bakker, A. B., Demerouti, E., \& Verbeke, W. (2004). Using the job demands-resources model to predict burnout and performance. Human Resource Management,43(1), 83-104.

[6] Farr, J. L., \& West, M. A. (1996). Innovation and creativity at work: psychological and organizational strategies. Chichester u.a.: Wiley.

[7] Fredrickson, B.L. (2001). The Role of Positive Emotions in Positive Psychology: $\square$ The Broaden-and-Build Theory of Positive Emotions. American Psychologist, 56(3), 218-226.

[8] Hakanen, J. J., Perhoniemi, R., \& Toppinen-Tanner, S. 
(2008). Positive gain spirals at work: From job resources to work engagement, personal initiative and work-unit innovativeness. Journal of Vocational Behavior, 73(1), 78-91.

[9] Hirst, G., Knippenberg, D. V., \& Zhou, J. (2009). A Cross-Level Perspective on Employee Creativity: Goal Orientation, Team Learning Behavior, and Individual Creativity. Academy of Management Journal,52(2), 280293.

[10] Hu, M. M., Horng, J., \& Sun, Y. C. (2009). Hospitality Teams Knowledge Sharing and Service Innovation Performance Questionnaire. PsycTESTS Dataset.

[11] Isen, A. M. (2001). An Influence of Positive Affect on Decision Making in Complex Situations: Theoretical Issues With Practical Implications. Journal of Consumer Psychology, 11(2), 75-85.

[12] Janssen, O. (2000). Job demands, perceptions of effortreward fairness and innovative work behaviour. Journal of Occupational and Organizational Psychology,73(3), 287-302.

[13] Kanter, R.M. (1983). The Change Masters. New York: Simon And Schuster.

[14] Koskinen, K. U., \& Vanharanta, H. (2002). The role of tacit knowledge in innovation processes of small technology companies. International Journal of Production Economics, 80(1), 57-64.

[15] Kotter, J. P., \& Heskett, J. L. (1992). Corporate culture and performance. New York: Free Press.

[16] Marquardt, M. J. (2002). Building the learning organization: Mastering the 5 elements for corporate learning. Palo Alto, CA: Davies-Black Pub.

[17] Maslach, C., \& Leiter, M. P. (1997). The truth about burnout: How organizations cause personal stress and what to do about it. San Francisco, Calif: Jossey-Bass.

[18] Meyer, A. D. (1982). Adapting to environmental jolts. Administrative Science Quarterly, 27, 515-537.

[19] Mumford, M. D., \& Gustafson, S. B. (1988). Creativity syndrome: Integration, application, and innovation. Psychological Bulletin, 103(1), 27-43.

[20] Nonaka, I., \& Takeuchi, H. (1996). The knowledgecreating company: How Japanese companies create the dynamics of innovation. Long Range Planning,29(4), 592.

[21] Öneren, M. (2008). Learning Organizations Approach in Companies. ZKU Journal of Social Science, 4(7), 163-178.

[22] Park, Y. K., Song, J. H., Yoon, S. W., \& Kim, J. (2014). Learning organization and innovative behavior. European Journal of Training and Development,38(1/2), 75-94.

[23] Pieterse, A. N., Knippenberg, D. V., Schippers, M., \& Stam, D. (2009). Transformational and transactional leadership and innovative behavior: The moderating role of psychological empowerment. Journal of Organizational Behavior,31(4), 609-623.

[24] Salanova, M., \& Schaufeli, W. B. (2008). A crossnational study of work engagement as a mediator between job resources and proactive behaviour. The International Journal of Human Resource Management, 19(1), 116-131.

[25] Schaufeli, W. B., Salanova, M., González-Romá, V., \& Bakker, A. B. (2003). The measurement of engagement and burnout: A two sample confirmatory factor analytic approach. Journal of Happiness studies, 3(1), 71-92.

[26] Scott, S. G., \& Bruce, R. A. (1994). Determinants Of Innovative Behavior: A Path Model Of Individual Innovation In The Workplace. Academy of Management Journal,37(3), 580-607.

[27] Senge, P. M. (1990). The fifth discipline: the art and practice of the learning organization. New York: Doubleday.

[28] Škerlavaj, M., Song, J. H., \& Lee, Y. (2010). Organizational learning culture, innovative culture and innovations in South Korean firms. Expert Systems with Applications,37(9), 6390-6403.

[29] Somunoğlu, S., Erdem, E., \& Erdem, Ü. (2012). A Study on Determining the Perception of Learning Organisation Applications by Health Sector Workers. Journal of Medical Systems,36(6), 39253931.

[30] Tseng, C. C. (2011). The influence of strategic learning practices on employee commitment. Browser Download This Paper.

[31] Van de Ven, A. H. (1986). Central problems in the management of innovation. Management science, 32(5), 590-607.

[32] Wang, Z., \& Wang, N. (2012). Knowledge sharing, innovation and firm performance. Expert systems with applications, 39(10), 8899-8908.

[33] Woodman, R. W., Sawyer, J. E., \& Griffin, R. W. (1993). Toward a theory of organizational creativity. Academy of management review, 18(2), 293-321.

[34] Yoon, S. W., Song, J. H., Lim, D. H., \& Joo, B. K. (2010). Structural determinants of team performance: The mutual influences of learning culture, creativity, and knowledge. Human Resource Development International, 13(3), 249-264. 